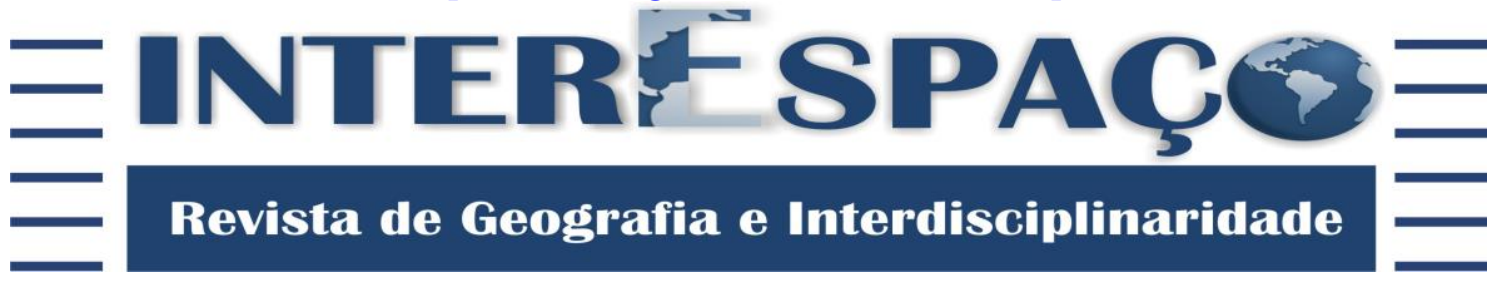

\section{A IMPORTÂNCIA HISTÓRICA DOS TESTES PSICOLÓGICOS PARA O ENSINO EM MINAS GERAIS NA DÉCADA DE 1930}

\author{
THE HISTORICAL IMPORTANCE OF PSYCHOLOGICAL TESTS FOR \\ TEACHING IN MINAS GERAIS IN THE 1930s
}

\section{UNA IMPORTANCIA HISTÓRICA DE PRUEBAS PSICOLÓGICAS PARA LA ENSEÑANZA EN MINAS GENERALES EN LA DÉCADA DE 1930}

\begin{abstract}
Renata Silva Cruz
Mestre em Educação pela Universidade Federal de Viçosa - UFV. Especialista em Educação Básica na Secretaria de Estado da Educação de Minas Gerais. Professora de Educação Básica da Prefeitura

Municipal de Viçosa. renatas_cruz@yahoo.com.br
\end{abstract}

\section{Denilson Santos de Azevedo}

Doutor em Educação pela Universidade de São Paulo - USP e Mestre em Educação pela Universidade Federal Fluminense - UFF. Professor Associado II do Departamento de Educação da Universidade Federal de Viçosa - UFV. dazevedoufv@gmail.com

Recebido para avaliação em 01/03/2017; Aceito para publicação em 31/10/2017.

\section{RESUMO}

O presente artigo tem por objetivo apresentar a importância histórica dos testes psicológicos, aplicados pelo Laboratório de Psicologia em Minas Gerais, na década de 1930; Apresentar as pesquisas desenvolvidas na Escola de Aperfeiçoamento em Belo Horizonte, MG, bem como verificar as possíveis contribuições desse trabalho, coordenado pela professora russa Helena Antipoff, quando prestou assessoria à secretaria do Interior em Minas Gerais na aplicação de testes de inteligência que visavam organizar as classes homogêneas por nível intelectual e as classes especiais. A aplicação de testes psicológicos foi um dos trabalhos pioneiros no Brasil. O laboratório adaptou os testes para a população de Minas Gerais a fim de conhecer as crianças mineiras obtendo informações sobre aspectos da personalidade, do desenvolvimento físico e social de cada aluno, além de realizar um levantamento do rendimento escolar e seus fatores determinantes para as práticas pedagógicas. Foram consultados documentos e fontes bibliográficas que tratam da implementação e dos estudos da referida escola. Esta análise permitiu identificar a diversidade de testes aplicados pelo laboratório e de como eles subsidiaram uma nova proposta de organização das classes, novos modelos pedagógicos que contribuíram para o ensino das crianças mineiras.

Palavras-chave: História da Educação; Testes Psicológicos; Laboratório de Psicologia.

\section{ABSTRACT}

The present article aims to present the historical importance of the psychological tests applied by the Laboratory of Psychology in Minas Gerais, in the 1930s; Present the research developed at the School of Improvement in Belo Horizonte, MG, as well as verify the possible contributions of this work, coordinated by the Russian professor Helena Antipoff, when she advised the interior secretary in Minas Gerais in the application of intelligence tests to organize the homogeneous classes by intellectual level and special classes. The application of psychological tests was one of the pioneer works in Brazil. The laboratory adapted the tests for the population of Minas Gerais in 
|Renata Silva Cruz | Denilson Santos de Azevedo|

order to get to know the children of Minas Gerais, obtaining information on aspects of the personality, physical and social development of each student, besides carrying out a survey of the school performance and its determining factors for the pedagogical practices. Documents and bibliographic sources dealing with the implementation and studies of this school were consulted. This analysis allowed to identify the diversity of tests applied by the laboratory and how they subsidized a new proposal of class organization, new pedagogical models that contributed to the teaching of the children of Minas Gerais.

Keywords: History of Education; Psychological Tests; Psychology Laboratory.

\section{RESUMEN}

Este artículo tiene como objetivo presentar la importancia histórica de las pruebas psicológicas aplicadas por el Laboratorio de Psicología en Minas Gerais, en la década de 1930; Presentar la investigación desarrollada en la Escuela de Perfeccionamiento en Belo Horizonte, MG, y para verificar las posibles contribuciones de este trabajo, coordinado por el profesor ruso Helena Antipoff, cuando se proporciona asesoramiento a la secretaría del Interior en Minas Gerais en la aplicación de las pruebas de inteligencia destinada a organizar clases homogéneas por nivel intelectual y clases especiales. La aplicación de pruebas psicológicas fue uno de los trabajos pioneros en Brasil. El laboratorio adaptado las pruebas para la población de Minas Gerais con el fin de conocer a los niños mineros reciben información sobre aspectos de la personalidad, el desarrollo físico y social de cada estudiante, además de la realización de un estudio del rendimiento escolar y sus determinantes para las prácticas pedagógicas, documentos y de la literatura que se ocupan de la aplicación y los citados estudios escolares fueron consultados. Este análisis nos permitió identificar la diversidad de las pruebas realizadas por el laboratorio y la forma en que subvencionan una nueva propuesta para la organización de las clases, los nuevos modelos pedagógicos que contribuyó a la enseñanza de los niños mineros.

Palabras clave: Historia de la Educación; Pruebas Psicológicas; Laboratorio de Psicología.

\section{INTRODUÇÃO}

O presente artigo versa sobre as atividades do Laboratório de Psicologia da Escola de Aperfeiçoamento de Belo Horizonte, MG, na década de 1930 em uma ação de organizar o ensino em Minas Gerais, bem como promover novas práticas pedagógicas.

Marcada por tensões, enfretamentos, avanços, recuos e debates educacionais, a década de 1930 nos oferece múltiplas possibilidades de estudos no campo histórico educacional. As Reformas neste período são abundantes e à escola foi atribuída a meta de combater o analfabetismo, visto como a "chaga" nacional e responsável pelo atraso do país.

Uma das reformas mais relevantes aconteceu em Minas Gerais em 1927, e se consolidou na década de 1930. Essa reforma foi pioneira nos avanços da educação no que diz respeito às ideias propagadas pela "Escola Nova". As principais mudanças aconteceram 
no ensino primário e na formação dos professores, com a implantação da Escola de Aperfeiçoamento ${ }^{1}$.

A escolha do objeto de pesquisa se justifica pela relevância de um conjunto de estudos, que nos chamam a atenção para história da educação mineira, que são os trabalhos publicados pela psicóloga russa Helena Antipoff e as alunas da Escola de Aperfeiçoamento. Estes estudos são resultados de investigações empreendidas no Laboratório de Psicologia da Escola de Aperfeiçoamento nos anos de 1930 (CAMPOS, 2012).

Estas pesquisas abordavam os ideais, interesses e desenvolvimento mental das crianças de Belo Horizonte, tendo como fundamento a chamada Pedagogia experimental que era o estudo empírico das condições de ensino e aprendizagem nas escolas da cidade, e a experimentação com métodos de ensino renovados. A base destes estudos era a Psicologia Educacional, que na época exerceu grande influência na Reforma, na elaboração do seu Programa.

Para este artigo, realizamos uma pesquisa bibliográfica a fim de conhecer a criação da Escola de Aperfeiçoamento e do Laboratório de Psicologia e identificar como estas instituições atuaram na Reforma do Ensino em Minas Gerais. Foram consultados artigos publicados na Revista de Ensino pelas alunas da Escola de Aperfeiçoamento, artigos da Professora Helena Antipoff, que se encontram no Centro de Documentação e Pesquisa Helena Antipoff, na biblioteca central da Universidade Federal de Minas Gerais e na Fundação Helena Antipoff em Ibirité-MG; documentos primários no Arquivo Público Mineiro que versa sobre o Programa de Ensino implementado pela Reforma.

Diante disso, para atender aos propósitos desse trabalho, traremos uma análise de alguns testes que foram aplicados nos Grupos Escolares de Belo Horizonte (MG) e do interior do estado, assim como de que forma estes testes contribuíram para organização do sistema de ensino e na adoção de novas práticas pedagógicas.

\section{OS TESTES}

A partir dos textos encontrados - escritos por Helena Antipoff e pelas professorasalunas colaboradoras do seu trabalho - referentes à educação e a psicologia experimental, verificamos que os métodos utilizados nessas pesquisas foram os testes inspirados na escala métrica Binet-Simon, adaptados "de acordo com as particularidades do meio e o

\footnotetext{
${ }^{1}$ A Escola de Aperfeiçoamento foi a primeira experiência, feita no Brasil, de implantação de instituição de ensino superior na área da Educação, e funcionou por duas décadas, tendo-se tornado instituição modelo na formação de educadores no país (CAMPOS, 2003).
} 
desenvolvimento das crianças" (ANTIPOFF, 1931, [n.p.]); e o método de "Experimentação Natural", apropriado para o estudo do caráter e da personalidade das crianças:

Em suma? Em todos os lugares em que a educação moderna se impõe, com aquelas escolas ativas, chega-se nitidamente a sentir a necessidade de ter à sua disposição meios de controles objetivos de desenvolvimento mental das crianças nas diferentes idades, meios estes, conhecidos sob o nome de Testes Mentais, ou ainda Testes Escolares, quando se trata de controlar objetivamente os progressos de ensino (ANTIPOFF, 1930/1992b, p. 59).

A aplicação dos testes psicológicos ocorreu concomitantemente à adaptação e à produção de escalas brasileiras de medida psicológica, especialmente a partir da adaptação da escala de inteligência Binet-Simon (ANTIPOFF, 1932/1992b).

O trabalho de Binet e Simon impactou os rumos do desenvolvimento da psicologia e da educação. A partir dele, surgiu uma grande discussão envolvendo a inteligência e suas implicações no processo educativo. Para esses autores, o espírito da criança, assim como seu corpo, crescia quantitativamente em função da idade e das experiências adquiridas naturalmente em contato com o mundo. Sendo assim, "eles propuseram diferentes tipos de testes para avaliar o desenvolvimento mental em diferentes idades" (ANTIPOFF, 1932/1992b, p. 74).

Partindo do pressuposto da idade, como padrão estabelecido, foi possível criar novas metodologias de ensino para grupos diferentes de crianças, focando suas necessidades específicas, bem como as fases do desenvolvimento infantil e as necessidades individuais. Nesse sentido, os testes se tornaram "os mecanismos adequados à estruturação racional de critérios de seletividades e de diferenciação entre turmas, planos e procedimentos didáticos" (DALBEN, 1998, p. 25).

O objetivo era identificar a criança com alguma dificuldade e buscar soluções alternativas que a ajudasse a superar essa dificuldade, sem impor-lhe um rótulo estigmatizante e limitador, pois, para Binet, toda criança podia melhorar se recebesse auxílio. Infelizmente, segundo Vieira (2008), inteligência passou a ser considerada algo inato, herdado, inevitável, o que influenciou muitos sistemas de educação que optaram em classificar os alunos por meio dos testes de inteligência.

Os testes psicológicos entraram no Brasil por meio da educação e, os laboratórios de psicologia tiveram papel importante nesta divulgação. Os laboratórios se dedicavam às pesquisas experimentais por meio dos testes, realizando estudos referentes ao desenvolvimento infantil, aos métodos de ensino e aprendizagem, aos problemas de fadiga 
mental, classificação de alunos para classes e problemas de leitura, escrita, linguagem e aritmética.

Segundo Gomes (2003, p. 4), a maior contribuição dos laboratórios foi, sem dúvida, a concepção de um saber científico, caracterizado "pelo desenvolvimento da atitude e da disciplina científica, a saber: curiosidade, criatividade, sistemática, rigor e humildade”. Nesse sentido, a atuação da psicologia no campo da educação foi atender uma demanda de organização de um sistema escolar, onde a realidade da educação era de elevados índices de analfabetismo, repetência e evasão escolar. Nesta realidade, os testes psicológicos ganharam espaço.

Por meio do Laboratório de Psicologia da Escola de Aperfeiçoamento, e da psicóloga Helena Antipoff, a utilização dos testes trouxe muitas implicações no diálogo entre psicologia e educação e marcou a história da educação em Minas Gerais. Durante o período em que esteve à frente do laboratório, vários testes foram aplicados às crianças dos diversos grupos escolares existentes na capital mineira, além de cidades do interior do estado. Nas fontes pesquisadas existe uma menção a 13 testes $^{2}$, sendo que alguns deles tiveram relação direta com o baixo desempenho dos alunos na aprendizagem da leitura e escrita e indicam fundamentos que poderiam comprometer a aprendizagem, o alto índice de repetência e o fracasso escolar.

Além dos testes aplicados às crianças com o objetivo de conhecê-las, Helena Antipoff ressaltou a importância da observação em situações naturais, pois, para ela, os testes eram incompletos, por serem realizados em condições artificiais, o que resultava em condutas artificiais (ANTIPOFF, 1992a). Conhecer a criança era algo complexo que exigia a aplicação de vários testes e a contraposição dos resultados com a observação direta da criança, pois “onde a observação coincide com o teste, o diagnóstico é mais seguro" (ANTIPOFF, 1931/1992b, p. 128).

A partir dos testes e das observações foi implementada uma série de estudos com o objetivo de conhecer a criança e o sistema de ensino mineiro. Nos resultados obtidos por meio dos boletins publicados pela educadora, identificamos que Helena Antipoff considerava a criança um ser em evolução, e seu desenvolvimento perpassava etapas biopsíquicas, e que cada criança realiza esse desenvolvimento em ritmos diferentes, o que foi possível classificá-las como precoces, "lerdas e retardadas" e em sua grande maioria em um ritmo médio (ANTIPOFF, 1934).

\footnotetext{
2 Teste Dearborn, Goodenough, Ballard, Teste de Vocabulário e Inteligência de Theodore Simon, Teste Prime, Teste E.A (Escola de Aperfeiçoamento), Teste B. Hor, Teste Limiar, Teste P.S, Teste Inicial, Teste dos Principiantes, Teste dos Novatos, Teste MM (Minhas mãos) (SOUZA, 2008).
} 
Os resultados dos testes também eram comparados com os apresentados por crianças de outros países. Sendo assim, verificamos que aplicação dos testes e a observação em sala, tinha por objetivos separar as crianças em classes homogêneas e classificá-las com relação às condições de maturidade de aprendizagem. Dessa forma, alguns testes utilizados por Helena Antipoff vão nos direcionar ao princípio da maturidade para alfabetização e nos darão elementos para uma prática pedagógica apropriada no ensino das crianças.

\section{O TESTE PRIME}

Em Belo Horizonte, com criação do Laboratório da Escola de Aperfeiçoamento e o trabalho do Laboratório de Psicologia, Helena Antipoff adaptou do Teste de Vocabulário de Inteligência de Binet-Simon, mesmo fundamento do teste $\mathrm{ABC}^{3}$, e aplicou em todo o estado de Minas Gerais, durante o ano de 1932. O então Teste Prime tinha como objetivos analisar as condições de maturidade para a aprendizagem escolar, assim como também avaliar o nível mental de crianças em idade escolar.

O Teste Prime era composto por trinta ${ }^{4}$ perguntas e aplicado às crianças novatas da $1^{a}$ série do ensino primário. Ele foi aplicado pela primeira vez em fevereiro de 1932 a todas as crianças dos dezoito Grupos Escolares de Belo Horizonte e nas vinte e cinco cidades do interior do estado que os compunham. Segundo um boletim publicado em 1932, o teste era de fácil aplicação e deveria durar apenas dez minutos.

Nas orientações para aplicação do teste é frisado que o aplicador deveria ter, em relação às crianças, uma atitude acessível, deveria procurar pelos modos, pelas palavras e pelo tom de voz, conquistar a confiança das crianças para que essas se sentissem à vontade. Caso a criança se negasse a participar não deveria insistir, deveria adiar a aplicação, para que em outro momento conseguisse esta espontaneidade. Além destas orientações, várias outras eram direcionadas aos aplicadores, e todas se baseando na naturalidade e espontaneidade (ANTIPOFF; CUNHA, 1932).

Dos cinco mil testes distribuídos na capital e no interior foram devolvidos ao laboratório quatro mil trezentos e quarenta e sete testes, os quais foram avaliados e os resultados publicados no Boletim nº 10 da Secretaria de Educação de 1932.

\footnotetext{
3 Os testes Abc foram aplicados por Lourenço Filho para verificação da maturidade para o aprendizado da leitura e escrita.

${ }^{4}$ Para conhecer as questões consultar: CRUZ, R. S. Considerações sobre a história da alfabetização em Minas Gerais e a participação de Helena Antipoff. 2016. 152 f. Dissertação (Mestrado em Educação) Universidade Federal de Viçosa, Viçosa, 2016.
} 
|Renata Silva Cruz | Denilson Santos de Azevedo|

Do total de alunos matriculados, $78 \%$ das crianças realizaram o teste. Os resultados forneceram indicações objetivas e interessantes acerca do nível mental da população escolar. O Teste Prime, por ser um teste destinado às crianças que entram pela primeira vez na escola, auxiliou na avaliação de alguns dos recursos intelectuais e o nível cultural geral dos diferentes grupos étnicos e sociais de Minas.

O teste revelou uma grande variedade cronológica nas crianças matriculadas na $1^{\text {a }}$ série, a variação era entre os 6 e 12 anos; o teste demonstrou que no interior do Estado as crianças entravam mais tarde na escola, por volta dos 8-9 anos; já na capital, esta entrada se dava mais cedo (6-7 anos), e isso justifica a variedade no nível intelectual dos alunos.

A análise minuciosa das 30 questões mostrou fatos curiosos e interessantes a respeito da inteligência e do vocabulário das crianças, percebeu-se que estes transpõem escola primária:

\footnotetext{
A criança conhece a cor dos objetos usuais; sabe identificar e nomear os animais (os mais comuns da região); maneja facilmente a noção da direita e da esquerda relativa a seu corpo; conhece o antônimo dos adjetivos mais correntes da língua; com lápis ela sabe traçar uma linha mais extensa do que a outra e imprimir-lhe direção determinada; conta sem enganar até 11 objetos, mas ainda não consegue realizar operações aritméticas (ANTIPOFF; CUNHA, 1932, p. 225).
}

A partir deste teste, identificando o que a criança já traz em sua bagagem cultural, os outros testes seriam realizados à medida que ela se desenvolvesse e progredisse. O teste seria referência para avaliação do seu desenvolvimento. Para Antipoff, essas aptidões e técnicas mentais fariam desabrochar o impulso da cultura escolar e intelectual e se desenvolveria rapidamente com a idade (ANTIPOFF; CUNHA, 1932).

Aos professores era sugerida uma atenção a essas diferenças. Eles deveriam oferecer às crianças oportunidades variadas de aprendizagem para que essas pudessem expandir todas as suas faculdades.

\section{TESTE LIMIAR}

O Teste Limiar começou a ser utilizado em substituição ao Teste Prime. Em relatório publicado pela Revista de Ensino, em 1934, as professoras-alunas começaram a perceber que os professores das escolas estaduais, já familiarizados com as perguntas, começaram a treinar as crianças para responderem ao questionário, comprometendo o ambiente considerado natural necessário à aplicação do teste. 
Aplicados entre os anos 1934 e 1935, o Teste Limiar tinha como objetivos analisar as condições de maturidade para a aprendizagem escolar e, também, avaliar o nível mental de crianças em idade escolar. De acordo com Pinheiro (1980), esse teste de aplicação individual foi um instrumento simples, econômico, rápido e que permitiu uma avaliação bastante precisa das condições de maturidade para a aprendizagem escolar e, ainda, avaliação de nível mental, ou seja, capacidade de aprendizagem.

O Limiar era composto por 30 (trinta) questões a partir das quais a criança era estimulada a pensar e dar respostas sobre objetos, sensações e situações relacionadas com o seu cotidiano como, por exemplo, cores de objetos, profissões com as quais ela convivia no seu ambiente, etc. As perguntas eram feitas pelo aplicador, que também anotava as respostas dadas pela criança. Fazia parte do material do teste, além da folha de respostas, palitos e caixas vazias de fósforos e uma chave de porta comum (FUNDAÇÃO HELENA ANTIPOFF, 1980).

\section{O TESTE B. HOR ${ }^{5}$}

O teste B. Hor seguia o mesmo princípio do Teste Limiar, ou seja, era um teste de vocabulário para medir o desenvolvimento escolar. Era composto de 34 questões, sendo 19 referentes à língua pátria e 15 à aritmética. Este teste era direcionado aos alunos repetentes ${ }^{6}$ e foi aplicado pela primeira vez em no final de 1932, para 3.396 crianças $^{7}$. Como todos os outros testes, não era levado em consideração o total absoluto de pontos, mas sim a relação com a idade cronológica, seguindo a fórmula número de pontos X 1000/ pela idade da criança.

Assim como o Teste Prime e o Limiar, o Teste B. Hor era acompanhado de uma orientação para ser aplicado em um ambiente o mais natural possível, levando os alunos a um ambiente de confiança e tranquilidade. O conteúdo dos testes era de acordo com o programa $^{8}$ em vigor, no qual deveria ser observado o conteúdo de Língua Pátria e Aritmética: "O pequeno teste que no fim do ano letivo o Laboratório de Psicologia elabora para alunos do primeiro ano, verificando a sua habilidade de leitura, escrita, ortografia e

\footnotetext{
${ }^{5}$ B. Hor deve significar Belo Horizonte (SOUZA, 2008, p. 136).

${ }^{6}$ Não fica muito claro se era aplicado apenas aos repetentes, pois na introdução do texto $A s$ classes do $1^{\circ}$ ano há uma referência sobre sua aplicação ser somente para os repetentes, mas no relato dos resultados faz menção em ter sido aplicado também aos novatos.

${ }^{7}$ Diferente do Prime o B. Hor foi aplicado apenas nos grupos escolares de Belo Horizonte e não em todo o estado.

${ }^{8}$ Decreto $n^{\circ}$. 8.094, de 22 de dezembro de 1927. Aprova os programas do ensino primário. Instruções para serem observadas nos programas de ensino.
} 
cálculo, não tem a pretensão de apreciar o trabalho escolar integral" (ANTIPOFF, 1934/1992b, p. 230).

O objetivo do teste também era o de avaliar o trabalho pedagógico dos professores nos grupos escolares, pois, segundo Antipoff, se fazia necessário verificar de que forma os novos métodos estavam sendo utilizados pelos professores em sala, bem como o material didático que estava sendo elaborado pelo Laboratório e as disciplinas de metodologia.

\section{INQUÉRITO - IDEAIS E INTERESSES DAS CRIANÇAS}

A primeira publicação do Museu da Criança ${ }^{9}$, realizada pelo Laboratório de Psicologia, em 1930, foi intitulada de "Os ideais e interesses das crianças". Para Helena Antipoff, este tipo investigação em psicologia era conhecido como psicotrópica ${ }^{10}$. Baseado nos estudos da pedagogia ativa, o conhecimento dos interesses das crianças era uma forma de motivá-las a aprender. O estudo, segundo Antipoff, se justificava como uma forma de orientar a educação das crianças, além de conhecer melhor o ambiente e as crianças do país:

Procurar determinar as necessidades, os gostos, os interesses, as aspirações, as ideias dos indivíduos de uma coletividade inteira, é procurar colher os vestígios materiais (se assim podemos exprimir-nos) das tendências psíquicas intimas de acordo com o eu. Realizando-se mediante inquéritos acerca das ocupações, dos jogos, das leituras preferidas, acerca das profissões a que aspiram os indivíduos (ANTIPOFF, $1930 / 2002$, p. 135).

Para Antipoff, este tipo de estudo revelava particularidades importantes como: ambiente social, tipo de cultura e o perfil da instrução pública do país. Dessa forma é possível perceber nos indivíduos influências familiares, da escola e das leituras que ele faz (ANTIPOFF, 1930/2002). Nos dizeres de Campos, na determinação da psicotropia, deveria ser considerada: o meio em que a criança vivia, sua educação, sua idade e a personalidade, ou seja, "um conjunto de fatores cuja interação constituiria a maneira específica do indivíduo ver as coisas” (CAMPOS, 2012, p. 211).

Segundo Antipoff (1930), era importante saber das próprias crianças quais eram seus interesses, para poder atingir seus gostos e, a partir deles, propor as leituras que pudessem alcançar os objetivos maiores da escolarização: educar a infância de forma integral. Ideia presente nos pressupostos da escola ativa, ou escola nova, "inspirada em ideais de participação ativa dos cidadãos na vida social e política, de desenvolvimento no

\footnotetext{
${ }^{9}$ O Museu da Criança foi um espaço criado pelo Laboratório de Psicologia para armazenar os resultados das pesquisas realizadas, com o objetivo de se tornar um local de consulta pelos professores, destes resultados.

${ }^{10}$ Conhecer as motivações das crianças, seus interesses.
} 
|Renata Silva Cruz | Denilson Santos de Azevedo|

sentido libertário das próprias relações sociais, ainda que ligadas a uma concepção fundamentalmente individualista do homem". Desse modo, na concepção ativista, mesmo que a participação ativa fosse considerada essencial às relações de comunicação com os outros, tais relações não deveriam "prejudicar a autonomia da consciência e a liberdade pessoal de escolha" (CAMBI, 1999, p. 515).

O teste era realizado com crianças da quarta série primária das diversas escolas públicas de Belo Horizonte. Foram distribuídos 10.000 testes para serem aplicados. Destes, 760 foram analisados, entre os quais se procurou priorizar os de mesmo ano escolar, nível mental "sensivelmente igual", embora de idades diferentes (ANTIPOFF, 1930/2002, p. 137). Para realizar este estudo, Helena Antipoff utilizou de um pequeno questionário, que ela denominava como método inquérito ${ }^{11}$, com as seguintes perguntas:

\footnotetext{
Qual o trabalho que prefere na escola? Qual o trabalho que prefere em casa? Qual o seu brinquedo preferido? Qual o livro ou história de que você mais gosta? Com que pessoa queria você parecer-se? Por quê? Quando for grande o que quer ser? Por quê? Que presente queria receber no dia de seu aniversário? Se você tivesse muito dinheiro, o que faria dele? (ANTIPOFF, 1930/2002, p. 137).
}

A pesquisa revelou que o interesse das crianças variava de acordo com a idade, influência do professor e o método que este utilizava nas aulas. "Deve-se cuidar para que o desinteresse das crianças não seja causado pela má forma de ensinar do professor" (CLAPARÈDE, 1934, [n.p]). Segundo Antipoff, este método de pesquisa possuía grande importância pedagógica. "Este tipo de pesquisa deveria ser feito todos os anos pelos professores e diretores dos grupos escolares para que os professores pudessem desenvolver os hábitos de ensino correspondentes ao interesse e necessidade das crianças" (ANTIPOFF, 1930/2002, p. 139):

O pedagogo muitas vezes desconhece a criança, exatamente por não lhe deixar a palavra suficientemente emancipada do eu do mestre ele próprio. À menor falta a criança comete, à menor incoerência, na opinião do pedagogo, intervém o mestre, que desvia o pensamento próprio da criança. Mas, antes de reagir e de corrigir a criança, cumpre deixá-la exprimir-se livremente a fim de lhe conhecer a mentalidade, a estrutura psicológica. $O$ mestre que conservou a criança durante muitos anos em sua classe se sente por vezes maravilhado com as respostas reveladas no inquérito; por vezes, ao contrário, as respostas desapontam o mestre: ele julgava mais inteligente seu aluno (ANTIPOFF, 1930/2002, p. 134).

\footnotetext{
${ }^{11}$ Segundo Antipoff o método do inquérito é recomendável para as iniciações dos pedagogos em pesquisa psicológica.
} 
Nota-se, portanto, que o método do inquérito inaugurou uma série de pesquisas sobre a criança mineira, trouxe muitas informações para os educadores e proporcionou às professoras-alunas uma formação necessária para lidar com a observação psicológica das crianças.

Identificamos, ainda, em nossa pesquisa, que havia uma publicação sobre este teste, comparando os resultados a cada 5 anos. Esses resultados mostram-nos dados interessantes sobre a preferência literária das crianças e são apresentados de forma gradativa: “[...] muito interesse, primeiramente, pela leitura de contos de fadas, depois, pelos livros de leitura escolar e de aventuras, ao passo que, pelos livros científicos, históricos e religiosos e romances, se mostram os alunos pouco interessados" (CASTRO, 1935/1992a, p. 156).

Maria Angélica de Castro, no boletim publicado em 1935, sobre "Os ideais e interesses das crianças no intervalo de 5 anos" ressalta que as diferenças nos resultados vão se modificando à medida em que o próprio ambiente, em Belo Horizonte, muda: a vida, o caleidoscópio político, os métodos escolares se modificam para uma tendência mais socializada e menos acadêmica (CASTRO, 1935/1992a, p. 157). Observa-se na Tabela 01 que já na primeira publicação sobre os interesses das crianças há uma preferência por livros de histórias, contos e lendas, ou seja, a literatura começava a fazer parte do interesse das crianças, que antes só tinham contato com os livros escolares.

Tabela 01 - Qual é o livro ou a História que você prefere?

\begin{tabular}{ccc}
\hline & Meninos & Meninas \\
\hline Contos e Lendas & $53,37 \%$ & $74,42 \%$ \\
Livros históricos & $11,34 \%$ & $3,91 \%$ \\
Livros de leitura escolar & $10,42 \%$ & $11,85 \%$ \\
Aventuras & $10,42 \%$ & $4,60 \%$ \\
Almanaques & $8,52 \%$ & $1,84 \%$ \\
Romances & $2,45 \%$ & $0,99 \%$ \\
Livros científicos & $1,53 \%$ & $0,92 \%$ \\
Livros religiosos & $0,61 \%$ & $0,23 \%$ \\
Diversos & $0,86 \%$ & 0,92 \\
\hline
\end{tabular}

Fonte: CASTRO, 1930/1992a, p. 91.

O interesse pela literatura estava inserido no contexto das transformações propostas no novo programa de ensino e o gosto das crianças pela leitura fazia parte da proposta da escola ativa. No entanto, havia uma preocupação com a criança que deixasse a escola primária, apenas com gosto pelas histórias da carochinha e os contos. Para Antipoff, 
|Renata Silva Cruz | Denilson Santos de Azevedo|

se deixando a escola, a criança não sabe ler outra coisa, mas apenas os contos expressos nas cartilhas, esta não lerá outro tipo de literatura e possivelmente se esquecerá do alfabeto:

\begin{abstract}
A escola ativa, a educação funcional se propõe outra finalidade, e as suas ambições são muito mais vastas. Está longe de limitar sua atividade e formar apenas a técnica, a ensinar a leitura, especialmente. Trata-se, antes de mais nada, despertar a necessidade de ler e desenvolver o gosto pela leitura. Uma vez provocado o interesse, todas as funções apropriadas, a atenção, a observação, a memória e o juízo, a reflexão e a imaginação, serão para isso ótimos colaboradores, que desempenharão sua tarefa de toda vida, deixando disso traços indeléveis. A escola tem por objetivo educar a criança e desenvolver-lhe a personalidade. Ora, o nível da personalidade, entre outros, se mede pelo teor de seus gostos, de seu interesse e dos ideias a que ela aspira (ANTIPOFF, 1930/2002, p. 154).
\end{abstract}

Assim, para a educadora, a investigação se faz necessária à medida que os planos escolares, as práticas pedagógicas e os materiais didáticos, bem como os literários, careciam de se conformar com o interesse da criança, de sua personalidade. Sobre isso, Kinkle (2003) nos mostra em seu trabalho que, até 1925 havia em Minas Gerais a prescrição do que se devia ler nos grupos escolares, no entanto, no Programa de $1925^{12}$, o ensino de leitura traz como objetivos da escolarização "despertar no aluno o desejo de ler; estimular nele a apreciação da leitura; habituá-lo à leitura recreativa, ensinando-lhe a arte de ler; fixar o hábito de ler por prazer" (Decreto nº 6.758/1925).

À escola cabia a função de criar este novo babitus ${ }^{13}$, ou seja, assumir a incumbência de formar o gosto pelo que era considerado como uma boa leitura, e permitindo em seu espaço somente a circulação daqueles livros considerados mais adequados aos objetivos da escolarização - aqueles aprovados pelo Conselho Superior, ou ao menos pelo diretor ou pelo professor. Assim, as representações que circulavam sobre o gosto infantil e a boa leitura ajudavam na produção e na escolha de livros para esse público.

Portanto, o inquérito sobre os ideais e interesses das crianças foi fundamental na tentativa de fazer com que o gosto pela leitura se constituísse em um habitus, mas para isso foi necessária uma mudança na prática pedagógica, bem como nas oportunidades disponíveis aos alunos de terem contato com a literatura. Abaixo algumas conclusões da pesquisa:

[...] nosso inquérito patenteia mais uma vez a necessidade urgente de prestar atenção rigorosa à leitura das crianças; é indispensável desenvolver as bibliotecas

\footnotetext{
12 Decreto $\mathrm{n}^{\circ} \cdot 6.758$, de $1^{\circ}$ de janeiro de 1925, que dispunha sobre o Programa do Ensino Primário do Estado de Minas Gerais.

13 Pierre Bourdieu considera que a escola, enquanto força formadora de hábitos propicia aos que se encontram direta ou indiretamente submetidos à sua influência, um "habitus cultivado". Consideramos aqui o babitus como a incorporação, pelos sujeitos que constituem a escola, da cultura disseminada em um determinado modelo escolar (FARIA FILHO, 2000).
} 
escolares criar bibliotecas circulantes para a mocidade; organizar clubs que teriam a cargo ensinar as crianças a ler os livros, a compreendê-los e a amá-los; outra medida consistiria em multiplicar as edições baratas para a mocidade e traduzir e adaptar as obras-primas da literatura mundial (ANTIPOFF, 1930, p. 36).

Dessa forma, este inquérito era realizado a cada cinco anos pelo Laboratório e os resultados publicados na Revista de Ensino e no Boletim de Minas Gerais. Após a primeira publicação, os resultados passaram a ser comparados com os anos anteriores e serviram de medida para utilização de novos métodos e novas práticas pedagógicas no sistema de ensino em Minas Gerais, que iam sendo inseridas no currículo da escola primária, como se pode conferir na seguinte citação:

A relação entre o primeiro e segundo inquérito mostra um crescimento no interesse pela literatura, isto se deve ao fato de algumas medidas tomadas pelo sistema escolar: criação de clube de leituras, biblioteca nas escolas, hora da história estabelecida na grade curricular, o comércio passou a oferecer mais opções de livros infantis (CASTRO; ANTIPOFF, 1936, [n.p.], grifo nosso).

Quanto à preferência curricular, a aritmética e a língua pátria variavam para os meninos e meninas. Entre as meninas, a preferência ${ }^{14}$ era a língua pátria, e entre os meninos a aritmética. Com relação aos livros de literatura, as crianças preferem os contos, apesar de serem já inadequados para a idade.

Os resultados obtidos com os testes foram comparados com os mesmos testes realizados em outros países e revelaram a ação do ambiente na determinação das tendências psicológicas das crianças. Os ideais e interesses das crianças mineiras pareceram mais limitados e menos diversificados do que das crianças dos outros países da Europa e Estados Unidos. Ao interpretá-los, Antipoff revela sua postura pedagógica e explica o ambiente que a criança está inserida e sugere que as crianças entrevistadas provinham de meios sociais modestos, tinham também menos horas diárias de estudos em relação às crianças estrangeiras $^{15}$ (CAMPOS, 2010).

Ao desenvolver os testes, Helena Antipoff também se deparou com o problema das crianças com deficiências físicas, mentais e com problema de comportamento. Essas crianças frequentavam as classes regulares das escolas públicas e não recebiam educação especializada. A trajetória escolar dessas crianças era marcada por uma série de reprovações e abandono da escola antes da conclusão do primário (CAMPOS, 2003).

\footnotetext{
${ }^{14}$ Para saber sobre o resultado das outras questões, conferir: ANTIPOFF, H. Ideais e interesses das crianças de Belo Horizonte e algumas sugestões pedagógicas. In: CAMPOS, R. H. F. (Org.). Helena Antipoff: textos escolhidos. São Paulo: Casa do psicólogo, 2002. p. 133-157.

${ }^{15}$ Naquela época as escolas públicas norte-americanas e europeias já funcionavam com período integral (CAMPOS, 2010, p. 46).
} 
|Renata Silva Cruz | Denilson Santos de Azevedo|

A partir desses resultados ela afirma que a atividade educativa deveria ser organizada de acordo com as necessidades, os interesses espontâneos e as aspirações das crianças. Mas se os resultados eram limitados, como enriquecer a experiência das crianças? Para Antipoff, era necessário, por meio da escola pública, prover às crianças de um ambiente suficientemente diversificado, harmonioso e rico em estímulos, no qual elas pudessem encontrar uma aplicação adequada à sua natureza. Por isso, a pesquisadora defende a observação psicológica como possibilidade de enriquecimento das práticas pedagógicas, e se preocupa com o impacto do ambiente social da criança na construção da sua cognição, mas via que escola poderia contribuir decisivamente no desenvolvimento das capacidades intelectuais das crianças (CAMPOS, 2012).

Além disso, o inquérito sobre os ideais e interesses das crianças se tornou base para tantas outras pesquisas desenvolvidas pelo Laboratório e pelo Museu, com relação à escola primária em Minas Gerais, entre elas, as pesquisas sobre "Escolologia"16 e as publicações dos pré-livros didáticos, que serão suporte pedagógico para a utilização do método global, como método de alfabetização nas classes primárias dos grupos escolares.

\section{CONSIDERAÇÕES FINAIS}

No período pesquisado, o discurso modernizador, orientado pelo ideal da Escola Nova, colocou sobre a escola a meta da eficiência, no sentido de garantir ao aluno um ensino sob medida, adequado à suas características e aptidões para a aprendizagem e suas necessidades de adaptar ao meio que o cerca. Nesta perspectiva, a eficiência do sistema escolar dependia de sua capacidade de atender às exigências do indivíduo e do meio. Do ponto de vista prático, isto se traduz em ofertar ao aluno um ambiente psicologicamente organizado para a aprendizagem e um ensino ativo, ou seja, a eficiência se torna uma questão da ciência e da técnica postas a serviço da ação pedagógica.

Neste sentido, diante do exposto, percebe-se que a utilização dos testes psicológicos na organização sistema de ensino em Minas Gerais, naquele momento histórico, de fato teve uma influência na organização da educação.

O discurso da ciência como base para educação encontrou subsídio na psicologia como um campo fundamental de medida e avaliação. Dando ênfase aos testes psicológicos,

\footnotetext{
16 Neologismo proposto por Antipoff, que tem como objeto de estudo a escola e tudo que com ela se relaciona (administração, prédio, higiene, material didático, regime escolar, organização das classes, características do ensino, métodos didáticos, as instituições auxiliares, enfim, o escolar).
} 
o Laboratório de Psicologia promoveu inúmeras pesquisas para traçar o perfil da criança mineira e suas condições cognitivas para aprender e se alfabetizar.

No entanto, muito mais que medir e avaliar, as pesquisas realizadas pelo Laboratório possibilitaram um conhecimento dos dados cognitivos e sociais das crianças de forma que pudesse haver uma organização do ensino público mineiro, bem como interferir nos processos de aprendizagem por meio da utilização de novos instrumentos didáticos, métodos de ensino e conteúdos. Além disso, o conhecimento da realidade socioeconômica dos alunos trouxe uma nova perspectiva: a de considerar a aprendizagem para além da inteligência, ou seja, de considerar que os fatores externos são influentes no processo de aprendizagem.

\section{REFERÊNCIAS}

ANTIPOFF, H. [1930]. O nosso Museu da Criança. In: CDPHA (Org.). Coletânea das obras escritas de Helena Antipoff. Vol. II - Fundamentos da Educação. Belo Horizonte: Imprensa Oficial, 1992a. p. 15-18.

. [1930]. Os ideais e interesses das crianças de Belo Horizonte. In: CDPHA (Org.). Coletânea das obras escritas de Helena Antipoff. Vol. II - Fundamentos da Educação. Belo Horizonte: Imprensa Oficial, 1992a. p. 61-100.

. [1930]. Psicologia Experimental - década de 1930. In: CDPHA (Org.). Coletânea das obras escritas de Helena Antipoff. Vol. I - Psicologia Experimental. Belo Horizonte: Imprensa Oficial, 1992b. p 59-63.

. [1931]. O desenvolvimento mental das crianças de Belo Horizonte. In: CDPHA (Org.). Coletânea das obras escritas de Helena Antipoff. Vol. I - Psicologia Experimental. Belo Horizonte: Imprensa Oficial, 1992b. p. 73-130.

[1932]. Organização das classes nos grupos escolares de Belo Horizonte. In: CDPHA (Org.). Coletânea das obras escritas de Helena Antipoff. Vol. I - Psicologia Experimental. Belo Horizonte: Imprensa Oficial, 1992b. p. 131-150.

Escolologia: Ensaios de pedagogia experimental. In: CDPHA (Org.). Coletânea das obras escritas de Helena Antipoff. Vol. II - Fundamentos da Educação. Belo Horizonte: Imprensa Oficial, 1992a. p. 111-117.

- Ideais e interesse das crianças brasileiras: conclusões. In: CDPHA (Org.). Coletânea das obras escritas de Helena Antipoff. Vol. I - Psicologia Experimental. Belo Horizonte: Imprensa Oficial, 1992b. p. 65-72.

ANTIPOFF, H.; CUNHA, M. L. A. Teste prime. Boletim n. 10. Belo Horizonte: Secretaria de Educação de Minas Gerais. Belo Horizonte, 1932.

CAMBI, Franco. História da Pedagogia. São Paulo: Editora UNESP, 1999. 
CAMPOS, R. H. F. Memória do Saber. Rio de Janeiro: Fundação Miguel de Cervantes, 2012.

Helena Antipoff (1892-1974) e a perspectiva sociocultural em Psicologia e Educação. 2010. 269 f. Tese (Concurso para Professor Titular) - Faculdade de Educação, Universidade Federal de Minas Gerais, Belo Horizonte, 2010.

Helena Antipoff. Recife: Fundação Joaquim Nabuco; Editora Massangana, 2010.

Helena Antipoff: razão e sensibilidade na psicologia e na educação. Estudos Avançados, São Paulo, v. 17, n. 49, p. 209-231, set./dez. 2003. Disponível em: < http://www.scielo.br/pdf/ea/v17n49/18405.pdf > . Acesso em: 15 fev. 2016.

CASTRO, M. A. Ideais e interesse das crianças de Belo Horizonte no intervalo de 5 anos. In: Coletânea das obras escritas de Helena Antipoff I (pp. 155-162). Org. pelo Centro de Documentação e Pesquisa Helena Antipoff, CDPHA. Belo Horizonte: Imprensa Oficial, 1992a. Publicado originalmente em 1935

CASTRO, M. A; ANTIPOFF, H. A Orientação das classes nos grupos escolares de Belo Horizonte. Boletim n. 19. Belo Horizonte: Secretaria da Educação e Saúde Pública: 1936. $138 \mathrm{p}$.

CLAPARÈDE, E. Psicologia da Criança e Pedagogia Experimental. Trad. Turiano Pereira e Aires da Mata Machado. Belo Horizonte: Imprensa Oficial do Estado de Minas Gerais, 1934.

DALBEN, A. I. L. F. A avaliação escolar: um processo de reflexão da prática e da formação do professor no trabalho. 2013. 267 f. Tese (Doutorado em Educação) Faculdade de Educação, Universidade Federal de Minas Gerais, Belo Horizonte, 1998. Disponível em: <http://www.bibliotecadigital.ufmg.br/dspace/handle/1843/FAEC85SJ7Q>. Acesso em: 29 jan. 2016.

FARIA FILHO, L. M. Dos pardieiros aos palácios: cultura escolar e urbana em Belo Horizonte. Passo Fundo, RS: Editora da Universidade de Passo Fundo, 2000.

GOMES, W. B. Pesquisa e prática em Psicologia no Brasil. 2003. Disponível em: <http://www.ufrgs.br/museupsi/ppnb.htm>. Acesso em: 22 jan. 2016.

KINKLE, K. Escolarização da leitura no ensino graduado em Minas Gerais (19061930). 2012. 190 f. Tese (Doutorado em Educação) - Faculdade de Educação, Universidade Federal de Minas Gerais, Belo Horizonte, 2003. Disponível em: <https://goo.gl/ozZMhL>. Acesso em: 22 jan. 2016.

PINHEIRO, I. M. Laboratório de Psicologia e Pesquisas Educacionais Edouard Claparède. In: Memorial Helena Antipoff. Ibirité, MG: Fazenda do Rosário, 1980. p. 77-83.

VIEIRA, R. C. O psicólogo e o seu fazer na Educação: contando uma outra história. 2008. 204 f. Tese (Doutorado em Educação) - Faculdade de Educação, Universidade Federal de Minas Gerais, Belo Horizonte, 2008. 